\title{
Ochy Curiel e o feminismo decolonial
}

\author{
Ana Paula Procópio da Silva* \\ Magali da Silva Almeida** \\ Renata Gonçalves***
}

A revista Em Pauta tem o prazer de apresentar para seu público a entrevista com a feminista decolonial Ochy Curiel, como parte da segunda edição do dossiê Questão Étnico-Racial e Antirracismo, organizado pelas professoras Ana Paula Procópio da Silva e Magali da Silva Almeida. Um diálogo que traz a possibilidade de conhecermos um pouco mais da trajetória militante e teórica desta intelectual negra, principalmente no que diz respeito à construção do feminismo decolonial e os desafíos colocados à luta antirracista, antissexista e anticapitalista.

Ochy Curiel nasceu em Santiago, na República Dominicana, onde se formou em Serviço Social e iniciou sua militância no movimento de mulheres. Quando mudou-se para a capital, Santo Domingo, teve contato com o feminismo mais organizado e com grande participação de mulheres lésbicas. Nesse período, final dos anos 1980, começou seu ativismo enquanto feminista negra e lésbica. Participou da criação da Casa pela identidade das mulheres afros, uma experiência que ela qualifica como maravilhosa, em especial por ser a primeira articulação no país a abordar simultaneamente a opressão sexual e racial. Dali surgiria o movimiento de mulheres negras da América Latina e do Caribe e, em 1992, sediaria o $1^{\circ}$. Encontro de Mulheres Negras na região.

Sua militância e sua teoria são atravessadas por outra de suas facetas, a música, que para ela também é uma forma de expressão de

\footnotetext{
* Doutora em Serviço Social pela UFRJ. É docente da Faculdade de Serviço Social da Universidade do Estado do Rio de Janeiro. Coordenadora do Programa de Estudos e Debates dos Povos Africanos e Afro-americanos (PROAFRO UERJ). E-mail: anapaulaprocopio@yahoo.com.br. ORCID: https://orcid.org/0000-0003-4420-1114.

** Doutora em Serviço Social pela PUC do Rio de Janeiro. Professora do curso de Serviço Social e Coordenadora do Programa de Pós-Graduação em Serviço Social do Instituto de Psicologia da Universidade Federal da Bahia. Coordena o Observatório de Racialidade e Interseccionalidade ORI-Núcleo de Pesquisa e Extensão sobre relações raciais, de gênero e classe e lutas sociais antirracistas._E-mail: quilombola_rio56@ yahoo.com.br. ORCID: https://orcid.org/00000001-7382-8480.

*** Doutora em Ciências Sociais pela Unicamp. É docente do curso de Serviço Social e do Programa de Pós-graduação em Serviço Social e Políticas Sociais da Universidade Federal de São Paulo, campus Baixada Santista, onde coordena o Núcleo de Estudos Reflexos de Palmares e o Núcleo de Estudos Heleieth Saffioti. E-mail: rengon 2011@gmail.com. ORCID: https://orcid.org/0000-0002-2470-9095.
} 


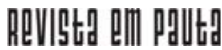

\} OCHY CURIEL E O FEMINISMO - SILVA, A. P. P.; ALMEIDA, M. S.; GONÇALVES, R. \}

DOI: $10.12957 /$ REP.2020.52020

resistência capaz de atingir outros grupos que não acessam nem a academia, por onde circula a maioria de seus escritos, nem os movimentos sociais, onde, em geral, estão pessoas mais politizadas. Foi a música, aliás, que a aproximou do feminismo. E desde então não parou mais. Como ativista do lesbofeminismo, analisou criticamente a imposição da heterossexualidade; também não poupou críticas à institucionalização do feminismo, que contribuiu para o recuo dos movimentos sociais.

Das andanças pela América Latina e Caribe ganham novos contornos as análises sobre gênero, raça e classe. $E$ aos poucos foi se identificando mais com o feminismo decolonial, mais complexo e mais situado em Abya Yala. A partir das margens, isto é, das distintas experiências e vivências de mulheres indígenas e afro-diaspóricas, Ochy Curiel percebeu que emergem conhecimentos e saberes que, ao mesmo tempo em que são expressões de resistência, transformam-se em novos horizontes epistêmicos de descolonização do conhecimento. A entrevista segue um percurso por meio do qual vamos conhecendo Ochy Curiel por ela mesma.

Boa leitura!

Em Pauta: Fale-nos um pouco de sua trajetória pessoal e política.

Ochy Curiel: Nací en República Dominicana, un país que comparte la Isla La Hispaniola (nombre colonial que coloco Cristobal Colón, pues antes el nombre ancestral de toda la Isla fue Haití) con el Estado-nación, Haití. Esa Isla fue el primer asentamiento europeo que luego se extendió al resto de las Américas.

Ahí viví alrededor de casi dos décadas de mi vida, particularmente en una ciudad del Norte, llamada Santiago. Soy hija de una mujer que fue maestra de escuela pública y un maestro de música, en principio con mucha precariedad, aunque nunca nos faltó nada. En esa ciudad cursé mi primaria, secundaria y la universidad. Allí estudie trabajo social y una especialización en Educación Superior, en el área de ciencias sociales. Ahí comencé a articularme al movimiento social, fundamentalmente de mujeres y también de los artistas que esa época denominamos, artistas alternativos, pues teníamos un compromiso social. Yo desde muy joven fui cantautora y tuve un tiempo que también me dediqué a la música.

De la ciudad de Santiago, me fui a Santo Domingo, la capital. Allí me articulé al movimiento feminista, a movimientos sociales culturales y también continué con el arte.

A finales de la década de los años 80 , construí, junto con otras compañeras, la Casa por la Identidad de las mujeres afros. Fue un proyecto maravilloso, el primero en el país en abordar el sexismo, el racismo y el sexismo. Nosotras contribuimos a conformar también el movimiento 


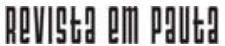

\} OCHY CURIEL E O FEMINISMO - SILVA, A. P. P.; ALMEIDA, M. S.; GONÇALVES, R. \}

DOI: $10.12957 /$ REP.2020.52020

de mujeres negras de América Latina y El Caribe y fuimos la sede del 1er Encuentro de mujeres negras en la región en 1992.

Fui una activista del movimiento lesbofeminista de la región, que comenzó a analizar la heterosexualidad obligatoria y al tiempo, fui parte de la corriente autónoma feminista que comenzó a cuestionar la institucionalización del feminismo y las políticas de desarrollo que se imponían desde el Norte hacia nuestros países y que implicó una pérdida de radicalidad en los movimientos sociales.

Posteriormente migré hacia México, luego a Brasil, después a Buenos Aires y ahora tengo ya 15 años en Colombia. Es aquí en Colombia que entró a trabajar en la academia en temas sobre sexo/género, raza y clase, desde una perspectiva decolonial, tanto en la docencia como en investigación, primero en la Universidad Nacional de Colombia, donde hice la maestría y el doctorado en antropología social, y luego en la Universidad Javeriana, en Bogotá. Desde que llegue a Bogotá he estado en el activismo particularmente en un proyecto artístico-político que es la Tremenda Revoltosa, una batucada feminista, antirracista, antimilitarista y que hace frente a las políticas neoliberales desde una postura autónoma.

En los últimos diez años, soy parte del feminismo decolonial. Conjuntamente con Yuderkys Espinosa construimos el Grupo Latinoamericano de Estudios, Formación y Acción Feminista (GLEFAS), un colectivo de pensadoras y activista de Latinoamérica y El Caribe que se posiciona desde esta perspectiva y que hoy es un importante referente para toda la región.

Em Pauta: Como esse percurso contribuiu para o desenvolvimento de seu trabalho teórico?

Ochy Curiel: Ha sido fundamental. En República Dominicana construí la conciencia feminista antirracista, autónoma, lesbo-feminista, artística y que luego seguí en los países donde migré. Todo ello que ha sido clave para los pensamientos y teorías que desarrollo. Posteriormente me fui identificando más con el feminismo decolonial que va complejizando ese pensamiento mucho más situado en Abya Yala (nombre decolonial de América Latina y El Caribe). Mi pensamiento teórico viene desde ahí, de la práctica política, desde todas esas corrientes políticas a las que he pertenecido

Em Pauta: Como você se aproximou das lutas feministas e do pensamento feminista?

Ochy Curiel: Primero a través del canto. Los movimientos sociales me buscaban para cantar, uno de ellos el movimiento feminista. A través de la 


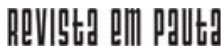

\} OCHY CURIEL E O FEMINISMO - SILVA, A. P. P.; ALMEIDA, M. S.; GONÇALVES, R. \}

DOI: $10.12957 /$ REP.2020.52020

conciencia que fui adquiriendo allí, comencé a componer canciones en torno a la subordinación de las mujeres, entre otras cosas. Luego ya me hago activista de este movimiento, primero de ese feminismo general, pero luego de un feminismo antirracista, luego lesbofeminista y ahora decolonial. Fue muchos después que entré a la academia como un espacio donde trabajo, pero que trato de llevar pensamiento crítico.

Em Pauta: Nos estudos de bell hooks encontramos várias análises das dificuldades que as mulheres negras encontram para serem reconhecidas como intelectuais. Quais são suas impressões sobre esta questão na América Latina e no Caribe?

Ochy Curiel: En esta región, y creo que más allá de ella, el concepto de intelectual ha estado siempre asociado a un sujeto hombre blanco y heterosexual que pareciera produce conocimiento de manera individual. Donde más se reproduce este imaginario es en las universidades, como instituciones que reproducen la colonialidad del saber. Es decir, donde se reproducen conocimientos que se espera sean objetivos y neutros, poco críticos y poco situados.

Es por ello que, en las universidades, en general, pensamientos y prácticas antirracistas, antisexistas, decoloniales son muy pocos. Las personas negras y afros, indígenas, que hemos podido llegar a las universidades son muy pocas por el racismo estructural que es parte de esa colonialidad del saber.

Cuando logramos llegar no somos reconocidas como intelectuales, aunque hay excepciones, sino como testimonios o materias primas para el conocimiento que construyen otros sobre nosotras o sobre nuestros pueblos y comunidades. No nos toman suficientemente en serio, no legitiman lo que estamos produciendo, porque aún se cree que no somos inteligentes y capaces para producir teorías, metodologías, conceptos que aporten a las ciencias.

Es por ello que es mucho el esfuerzo el que hay que hacer para lograr que se nos reconozca como intelectuales y no solo como activistas. Todo el tiempo estamos produciendo pensamiento, en general crítico, porque partimos de nuestras realidades situadas. Debemos presionar para que ese imaginario de lo que se supone es una intelectual desaparezca. Debe ser parte de nuestra lucha en todos los espacios donde nos encontremos.

Em Pauta: No Brasil, reconhece-se a existência de um movimento de mulheres negras, mas não há consenso acerca do feminismo negro. Existe um pensamento feminista negro? Qual a sua concepção a respeito? 


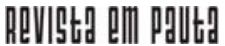

\} OCHY CURIEL E O FEMINISMO - SILVA, A. P. P.; ALMEIDA, M. S.; GONÇALVES, R. \}

DOI: $10.12957 /$ REP.2020.52020

Ochy Curiel: El concepto de feminismo negro es una adaptación del Black Feminism de EEUU. Es un concepto muy reciente. Desde que surgió el activismo de mujeres negras, a finales de la década de los 70 y 80 nos denominamos como parte del movimiento de mujeres negras, fuéramos feministas o no.

Más allá de que crea que feminismo negro responde al impacto que tienen las teorías y propuestas de las afroamericanas de EEUU, lo cual demuestra una subordinación de nuestras producciones en relación a lo que se produce en Estados Unidos, no obstante seamos afros, el posicionarse como feminista negra explica un lugar de enunciación importante que no se limita a una política de identidad, como bien podría entenderse desde ser "mujeres negras o afros, sino una lucha contra todos los sistemas de opresión (racismo, sexismo, heterocentrismo, clasismo etc.). Pero incluso hay diferencias entre las que podrían denominarse feministas negras. Algunas, por ejemplo, consideran que es una apuesta solo para mujeres negras por las experiencias de racismo, sexismo, clasismo, heterosexismo que les atraviesa, otras tienen una perspectiva más decolonial, que articulan una lucha más compleja, entendiendo que todos esos sistemas de dominación son parte de un patrón mundial de poder, definido como Aníbal Quijano como colonialidad del poder. Es decir, no podemos decir que exista una homegenidad en las maneras que se entiende el feminismo negro, hay distintas concepciones sobre ello, y obviamente diferencias en como se entiende la práctica política desde este posicionamiento.

Em Pauta: Você tem se debruçado a escrever sobre o feminismo decolonial. Como você o define? Quais são as características que o distancia do feminismo hegemônico?

Ochy Curiel: El feminismo decolonial es una de las corrientes más contemporáneas que complejiza y revisa postulados importantes del feminismo hegemónico, incluso lo cuestiona. Retoma y reconoce buena parte de las propuestas del feminismo negro en hacer una imbricación de "raza, clase, sexo y sexualidad, cuestionando las perspectivas que consideran que todas las mujeres tenemos un sistema sexo/género compartido. Retoma los aportes del lesbianismo feminista en entender que la heterosexualidad no se limita a una práctica sexual, sino que es un régimen político que atraviesa todas las relaciones sociales, económicas, culturales, sociales; retoma aportes importantes de movimientos de mujeres y feminismos indígenas en darle importancia a la construcción comunitaria, retoma postulados claves de la corriente autónoma latinoamericana que cuestionó desde la década de los 90 la institucionalización del feminismo, producto de políticas de desarrollo que imponen instituciones como el Fondo Monetario Internacional, el Banco Mundial, los estados y la cooperación del Norte, que hace perder 


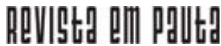

\} OCHY CURIEL E O FEMINISMO - SILVA, A. P. P.; ALMEIDA, M. S.; GONÇALVES, R. \}

DOI: $10.12957 /$ REP.2020.52020

radicalidad al feminismo y hace depender a los movimientos a las agendas definidas por estas instituciones, señalando la importancia de la autonomía y la autogestión como principio étnico-político. Retoma aportes del feminismo postcolonial en sus análisis sobre la violencia epistémica y colonialismo discursivo que hacen feministas del Norte con mujeres del Ilamado "Tercer Mundo" asumiéndolas solo como objeto y sin agencia frente a los sistemas de dominación. Es decir retoma elementos claves de los feminismos críticos, hechos fundamentalmente por mujeres afros, indígenas, lesbianas feministas, mujeres del "Tercer Mundo", muchas de las cuales hemos sido pioneras en estas corrientes, y las articula a las propuestas del proyecto modernidad/colonialidad quienes hacen una analizan como es imposible separar el mundialización del capitalismo del colonialismo y la modernidad occidental, trilogía que género jerarquías raciales, sociales, sexuales, geopolíticas, que consideró a unos como humanos y otros como no humanos y aunque surge en 1492, con el colonialismo, esas jerarquías aún permanece, lo que explica el concepto de colonialidad.

La critica fundamental que le tenemos al feminismo hegemónico es sigue considerando un patriarcado universal y muy poco aborda el racismo, en sus teorías y prácticas. Es un feminismo institucionalizo que pacta con las instituciones que fomentan esas jerarquías, se mueve en las lógicas de la democracia liberal y muy poco cuestiona la colonialidad, al contrario, la reproduce.

El feminismo decolonial, tiene un compromiso en superar la política de identidad y consolidar un proyecto político de coalición de diferentes pueblos y comunidades, no es separatista. Propende por un proyecto de liberación de múltiples sujetos subalternos atravesados por todos los sistemas de opresión, pero a la vez rescata todas las resistencias y luchas que se han hecho frente a esos sistemas.

Em Pauta: $\quad$ Numa entrevista feita aqui no Brasil em 2017 você afirmou que a interseccionalidade é uma proposta liberal. Então não seria possível uma análise interseccional crítica?

Ochy Curiel: Si es posible, siempre y cuando se tenga claro los límites de la propuesta hecha por Kimberle Crenshaw, autora del concepto. Es crítica en tanto visibiliza la articulación que existe entre raza clase, sexualidad, etc. Reconoce la imbricación y eso ya es un gran avance. Eso no es nuevo, antes de Crenshaw, ya lo había analizado el Colectivo Rio Combahee, Patricia Hill Collins, muchas de nosotras en Abya Yala, Sueli Carneiro, Jurema Wernerk, yo misma, entre muchas otras.

El problema de la interseccionalidad es que no pregunta cómo se producen las identidades y diferencias que producen los sistemas de opresión. ¿por qué soy negra?, ¿porque soy indígena? ¿porque soy les- 


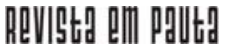

\} OCHY CURIEL E O FEMINISMO - SILVA, A. P. P.; ALMEIDA, M. S.; GONÇALVES, R. \}

DOI: $10.12957 /$ REP.2020.52020

biana? Las respuestas: Soy negra o indígena por el racismo, soy lesbiana por el heterosexismo. Es decir, más allá de que utilicemos estas categorías para articularnos políticamente, debemos saber que esos lugares han sido producidos por la colonialidad. Nuestras luchas por tanto, no se limitan a reconocer las identidades y las diferencias, sino a acabar con los sistemas de dominación. La interseccionalidad no profundiza sobre eso. La interseccionalidad es liberal, pues solo reconoce ejes de diferencias. No se trata solo de una cuestión teórica o conceptual, sino de una cuestión que tiene implicaciones para nuestras prácticas políticas.

Em Pauta: As identidades como questão política têm sido bastante atacadas pela esquerda brasileira e vimos crescer um discurso de retorno da centralidade da classe como forma de luta prioritária. Como avalia esse processo?

Ochy Curiel: Pues si bien para un proyecto de decolonización radical las identidades no pueden ser el objetivo final, son también importantes pues ellas han permitido reconocer una historia política de opresión y de resistencia. En estas sociedades tan racistas como las que tenemos en Abya Yala, que ha negado lo negro, asumido como lo feo, lo irracional e inhumano, reconocerse negra desde el orgullo y desde la autoafirmación, es un acto de resistencia. Igual reconocerse lesbiana en sociedades tan heterosexistas. Por tanto, sin importantes en las luchas, pero insisto, no son suficientes para un proyecto de liberación.

Que la izquierda latinoamericana y caribeña siga asumiendo que la lucha más importante es la de clase, solo muestra su racismo y su eurocentrismo. La izquierda en general ha bebido de las teorías europeas. En esta región y en cualquier lugar del mundo, todas las relaciones están marcadas por la "raza" (entendiéndola como ficción, como idea, no porque existan), por el sexo/género, la sexualidad, la geopolítica y todo está en conexión, está entrelazado. Seguir asumiendo que la clase es lo determinante, es una visión totalmente errada y limitada.

Em Pauta: Recentemente, você disse aqui no Brasil que as mulheres precisam ser mais radicais. O que significa?

Ochy Curiel: Considero que en general, sobre todo los movimientos que conozco son muy institucionales Parecería que no se puede hacer una lucha que no pase por el Estado. Tal vez esto tiene que ver con las características de Brasil, uno de los países que más tarde entró a la democracia. La verdad que conozco muy pocos proyectos políticos que se posicionan desde la autonomía política. Pero además pienso que muchos colectivos 


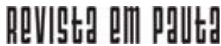

\} OCHY CURIEL E O FEMINISMO - SILVA, A. P. P.; ALMEIDA, M. S.; GONÇALVES, R. \}

DOI: $10.12957 /$ REP.2020.52020

están parados muy desde la identidad como su último fin político. Aunque obviamente hablo de los colectivos y organizaciones que conozco un poco.

Em Pauta: Esta radicalidade está presente no feminismo decolonial? É possível uma radicalidade feminista que seja também anticapitalista, antirracista e antissexista?

Ochy Curiel: Es que un proyecto feminista decolonial que no sea antirracista, anticapitalista, antisexista, no es decolonial. Pero además este proyecto parte de nuestra historia como continente. Se desengancha del síndrome colonial, de las lógicas liberales, se sostiene desde la autonomía política frente a las instituciones que sostienen la colonialidad como el Estado colonial, la cooperación internacional, los partidos. Además, no piensa que las luchas deben ser particulares, las feministas por allá, la gente negra por allá, o los indígenas. Todas las luchas son nuestras. Propendemos por acciones colectivas donde la construcción comunitaria sea el centro del sentir-pensar, del accionar, de la resistencia, de la creación de otro mundo, donde reconozcamos conocimientos, luchas y haceres ancestrales y actuales de la gente del común, implica una lucha no solo centrada en la escritura centremos sino en variadas formas del hacer que son también políticas, como la culinaria, el arte, la espiritualidad. Eso es para mi la radicalidad.

Em Pauta: Como aplicar a radicalidade deste feminismo no cotidiano das mulheres negras nestes tempos de pandemia do coronavírus (com crescimento da violência doméstica, mortes nas periferias etc.)?

Ochy Curiel: La pandemia del COVID-19 ha venido a develar lo que ya sabíamos: una desigualdad social impresionante con sus racismos, sexismos, heterosexismos y empobrecimiento. Devela además que la acumulación capitalista es un sistema de muerte. A pesar de que el COVID afectó a la gente europea, va afectar más a la gente de Abya Yala y de África, porque hace tiempos que nuestros sistemas de salud son precarios y privatizados, porque la gente no aguanta el confinamiento porque debe salir a buscar que comer cada día. Tenemos aproximadamente un $80 \%$ de mercado informal en la región. En todo eso, los gobiernos van a priorizar el mercado y no salvar vidas, mucho menos aquellas vidas que aun no se consideran suficientemente humanas, como la gente empobrecida que en general es negra e indígena, como está pasando en muchos países, sobre todo en Brasil.

En todo esto, habrá una vuelta al totalitarismo a través del poder del estado, unido a la militarización y el control de la vida. Habrá más desempleo, endeudamiento y empobrecimiento de nuestra gente. 


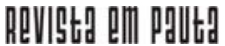

\} OCHY CURIEL E O FEMINISMO - SILVA, A. P. P.; ALMEIDA, M. S.; GONÇALVES, R. \}

DOI: $10.12957 /$ REP.2020.52020

¿Ante eso qué debemos hacer? Lo que los pueblos indígenas y afros nos han venido diciendo hace tiempos y que las mujeres negras y populares hacen todos los días. Tener otra racionalidad que no sea la del sistema de muerte, como ha hecho la modernidad occidental que a través del colonialismo y el capitalismo ha considerado que la naturaleza debe ser explotada, que es un objeto, igual que las personas que viven en comunidades, para la acumulación.

Debemos retomar esa ancestralidad, donde la naturaleza debe ser cuidada para la vida, porque es parte de nosotrxs, debemos tener otra ética del consumo que no implique comprar artículos que no necesitamos. Debemos evitar el individualismo que nos ha llevado esa colonialidad, que se exacerbará luego de la pandemia. La colectividad, los lazos comunitarios deben ser nuestra prioridad. Todo eso es necesario hacerlo a través de las coaliciones entre movimientos sociales, todos apuntando a un proyecto de vida y de solidaridad. A eso le ha apostado el feminismo decolonial, porque lo hemos aprendido de nuestros pueblos indígenas, afros y populares.

Em Pauta: Para você quais são as pautas na agenda de lutas globais capazes de unificar os movimentos sociais identificados com o campo progressista e anticapitalista?

Ochy Curiel: No creo en las agendas, es un vocabulario y una práctica institucional y colonial. Creo que los proyectos políticos, esos que podemos desarrollar desde cualquier lugar. Desde mi apuesta feminista decolonial, todos los movimientos que realmente crean en la transformación social, que crean que es posible un proyecto para la vida y no para la muerte, deben sostener y promover una lucha antirracista, anticapitalista, antisexista, pero además una lucha para derribar las fronteras, un proyecto de este tipo no puede ser nacionalista; debe implicar acciones políticas solidarias, todo eso desde tantas maneras del hacer político: arte, academia crítica, en las calles, en las redes sociales... Esa es la apuesta más urgente en estos momentos.

DOI: $10.12957 /$ rep.2020.52020

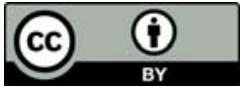

A Revista Em Pauta: Teoria Social e Realidade Contemporânea está licenciada com uma Licença Creative Commons Atribuição 4.0 Internacional. 